\title{
Oestrogen-regulated protein SLC39A6: a biomarker of good prognosis in luminal breast cancer
}

\author{
Maryam Althobiti ${ }^{1,2}$ (D) Khloud A. El-sharawy ${ }^{1,4} \cdot$ Chitra Joseph $^{1} \cdot$ Mohammed Aleskandarany $^{1} \cdot$ Michael S. Toss $^{1}$. \\ Andrew R. Green ${ }^{1,3} \cdot$ Emad A. Rakha $^{1,5}$
}

Received: 7 December 2020 / Accepted: 15 July 2021 / Published online: 28 August 2021

(c) The Author(s) 2021

\begin{abstract}
Purpose The outcome of the luminal oestrogen receptor-positive $(E R+)$ subtype of breast cancer $(B C)$ is highly variable and patient stratification needs to be refined. We assessed the prognostic significance of oestrogen-regulated solute carrier family 39 member 6 (SLC39A6) in BC, with emphasis on ER + tumours.

Materials and methods SLC39A6 mRNA expression and copy number alterations were assessed using the METABRIC cohort $(n=1980)$. SLC39A6 protein expression was evaluated in a large $(n=670)$ and annotated series of early-stage (I-III) operable BC using tissue microarrays and immunohistochemistry. The associations between SLC39A6 expression and clinicopathological parameters, patient outcomes and other ER-related markers were evaluated using Chi-square tests and Kaplan-Meier curves.

Results High SLC39A6 mRNA and protein expression was associated with features characteristic of less aggressive tumours in the entire BC cohort and ER + subgroup. SLC39A6 protein expression was detected in the cytoplasm and nuclei of the tumour cells. High SLC39A6 nuclear expression and mRNA levels were positively associated with ER + tumours and expression of ER-related markers, including the progesterone receptor, forkhead box protein A1 and GATA binding protein 3. In the ER + luminal BC, high SLC39A6 expression was independently associated with longer BC-specific survival (BCSS) $(P=0.015$, HR $0.678,95 \%$ CI $0.472-0.972)$ even in those who did not receive endocrine therapy $(P=0.001, H R 0.701$, 95\% CI $0.463-1.062$ ).
\end{abstract}

Conclusion SLC39A6 may be prognostic for a better outcome in ER + luminal BC. Further functional studies to investigate the role of SLC39A6 in ER + luminal BC are warranted.

Keywords SLC39A6 $\cdot$ ER-positive breast cancer $\cdot$ ER-related marker $\cdot$ Prognosis

Emad A. Rakha

emad.rakha@nottingham.ac.uk; Emad.rakha@nuh.nhs.uk

1 Division of Cancer and Stem Cells, School of Medicine, The University of Nottingham, University Park, Nottingham NG7 2RD, England

2 Department of Clinical Laboratory Science, College of Applied Medical Science, Shaqra University 33, Shaqra 11961, Saudi Arabia

3 Nottingham Breast Cancer Research Centre, Division of Cancer and Stem Cells, University of Nottingham Biodiscovery Institute, University Park, Nottingham NG7 2RD, England

4 Faculty of Science, Damietta University, Damietta, Egypt

5 Present Address: Department of Histopathology, School of Medicine, The University of Nottingham, City Hospital Campus, Hucknall Road, Nottingham, NG5 1PB, UK

\section{Introduction}

The oestrogen receptor-positive $(\mathrm{ER}+)$ tumours comprise $70-80 \%$ of breast cancer (BC). Approximately $30-50 \%$ of patients with $\mathrm{ER}+\mathrm{BC}$ do not respond to endocrine therapy, which further highlights the heterogeneity of these tumours in terms of behaviour and response to therapy [1, 2]. Analysis of gene expression in BC and assessments of the prognostic and predictive value of novel biomarkers [3, 4] have demonstrated the need to refine the classification of patients with $\mathrm{BC}$ in order to more accurately reflect tumour heterogeneity and tailor personalised therapeutic approaches $[5,6]$. Several molecular biomarkers have been studied in $\mathrm{ER}+$ luminal $\mathrm{BC}$ in an attempt to refine its classification with emphasis on ER-related genes including progesterone receptor (PgR), forkhead box protein A1 (FOXA1), GATA 
binding protein 3 (GATA3) and trefoil factor 1 (TFF1) [7-9]. In a previous study of $\mathrm{BC}$, a recurrence gene signature was identified, which included solute carrier family 39 member 6 (SLC39A6) [10]. SLC39A6 is an oestrogen-regulated gene that is upregulated in $\mathrm{ER}+\mathrm{BC}$ and positively correlated with ER status $[11,12]$. SLC39A6, also known as LIV-1 and ZIP6, is encoded on chromosome 18q12.2 [13] and expressed at high levels in hormonally controlled tissues [14].

SLC39A6 protein localises to the endoplasmic reticulum, whilst the N-terminal cleaved form is present on cell membranes [15]. SLC39A6 is a member of the ZIP family of transporters, which control zinc homeostasis by regulating the influx of zinc from extracellular to intracellular spaces [16]. The zinc transport function of SLC39A6 plays an important role in cellular metabolism $[15,17$, 18]. Zinc is required for a variety of cellular processes, including immune activity, protein synthesis, nucleic acid metabolism, cell proliferation, tissue repair and cell division [19], and low zinc levels can lead to metabolic disorder and inhibit cell growth [20]. Zinc is also involved in several signalling pathways in BC. For instance, zinc enters cells via SLC39A6-mediated transport and activates Akt, which inhibits glycogen synthase kinase 3 beta (GSK-3 $\beta$ ). In turn, deactivation of GSK-3 $\beta$ can affect Snail and downregulate E-cadherin (CDH1), epidermal growth factor receptor (EGFR) and MAPK [15].

Overexpression of SLC39A6 has been related to the progression of several types of cancer, including breast [13, 18], prostate [21], pancreatic [23], cervical [24] and liver cancer [25]. An in vitro study suggested that SLC39A6 is involved in metastasis in BC, as overexpression of SLC39A6 promoted the epithelial-mesenchymal transition (EMT) [15]. In studies using a limited number of patients, high SLC39A6 protein expression was associated with a better prognosis in $\mathrm{BC}(n=111)[26,27]$. These observations highlight the need to evaluate the prognostic value of SLC39A6 expression in $\mathrm{BC}$, especially in ER + tumours. Therefore, this study aimed to determine the prognostic value of SLC39A6 by assessing the associations between SLC39A6 protein expression, mRNA expression and gene copy number with clinicopathological parameters, expression of other key ER-related proteins and patient outcomes utilising large, well-characterised $\mathrm{BC}$ cohorts, with an emphasis on the luminal ER + subtype.

\section{Materials and methods}

\section{SLC39A6 mRNA expression (METABRIC cohort)}

SLC39A6 mRNA expression and gene copy number (CN) aberrations were assessed using the Molecular Taxonomy of Breast Cancer International Consortium (METABRIC) cohort of early-stage invasive BC (stage I-III; $n=1980$ ). Both SLC39A6 mRNA and CN data were not available for all cases $(n=1980)$; Supplementary Table 1.

DNA and RNA were isolated from freshly frozen tumour samples and transcriptional profiling was performed using the Illumina HT-12V3 platform, as previously described [6]. This cohort included 1473 cases of ER $+B C$. The clinicopathological features of the METABRIC cohort are summarised in Supplementary Table 2. The association of $S L C 39 A 6$ and ER-related genes, including $P g R, T F F 1$ and GATA3 was examined.

\section{External validation}

The prognostic significance of SLC39A6 mRNA expression was examined in Bc-GenExMiner v4.0 (Breast Cancer Gene-Expression Miner v3.0), online data set available at http:// bcgenex.centregauducheau.fr. The associated SLC39A6, and different prognostic parameters: age, grade, nodal, Nottingham prognostic index (NPI), Oestrogen receptor (ER) and molecular subtypes and Univariate analyses were performed [28].

\section{SLC39A6 protein expression (Nottingham cohort)}

SLC39A6 protein expression was assessed in tissue microarray from a well-characterised cohort of patients with primary invasive BC $(n=670)$ who presented to Nottingham City Hospital between 1989 and 1998. Prospectively maintained clinicopathological data were available, including age at diagnosis, histological type, tumour size, lymph node status, Nottingham Prognostic Index (NPI) (categorised as good, NPI score $\leq 3.4$; moderate, NPI 3.41-5.4; poor, NPI > 5.4) and lympho-vascular invasion (LVI) [29].

Patients were treated uniformly, based on tumour features, NPI and hormone receptor status. Endocrine therapy was given to patients with ER + tumours and a high NPI score (>3.4); patients with low NPI scores $(\leq 3.4)$ did not receive adjuvant therapy [30]. Premenopausal patients with moderate or high NPI scores were candidates for chemotherapy; postmenopausal patients with ER + tumours and moderate or high NPI scores only received endocrine therapy. None of the patients received neoadjuvant therapy or HER 2 targeted therapy. Outcome data were retrieved, including breast cancer-specific survival (BCSS; time in months from primary surgery to death due to $\mathrm{BC}$ ), distant metastasis-free survival (DMFS; time in months from primary surgery until first detection of distant metastasis) and recurrence-free survival (RFS; time in months from primary surgery until first detection of ipsilateral recurrence) [20]. The clinicopathological 
features of the Nottingham cohort are summarised in Supplementary Table 2. Data for ER, PgR, HER2, Ki67, GATA3, FOXA1 and TFF1 were available as previously published $[13,15,18,21]$ [31]. ER and PgR positivity were defined as positive nuclear staining in $\geq 1 \%$ of the invasive tumour cells $[13,21,23] ; 75 \%$ of the patients had ER + tumours. HER2 positivity was defined as strong positive membranous staining in $\geq 10 \%$ of the invasive tumour cells (score +3 ). HER2 gene amplification status was assessed in borderline cases (IHC score + 2) using chromogenic in situ hybridisation [32]. Ki67 expression was dichotomised as low or high using $10 \%$ as a cut-off point [33].

\section{SLC39A6 immunohistochemistry}

The specificity of the anti-SLC39A6 antibody (rabbit polyclonal, AA170320; LSBio, Cambridge, UK) was validated by Western blotting using MCF7, MDA-MB-231 and HeLa cell lysates; the cells were obtained from the American Type Culture Collection (Rockville, MD, USA). A mouse primary monoclonal beta-actin antibody (1:5000, Sigma-Aldrich) was used as a loading control. When used at a dilution of 1:1500, the SLC39A6 primary antibody revealed a single specific band at the predicted molecular weight of $85 \mathrm{kDa}$ (Supplementary Fig. 1). Moreover, prior to immunostaining the tissue microarrays (TMAs), full-face tissue sections from 20 randomly selected $\mathrm{BC}$ cases were stained using the SLC39A6 antibody to assess the staining distribution and validate the use of TMAs to assess SLC39A6 protein expression.

BC tissue samples from the Nottingham cohort were arrayed using a TMA Grand Master® (3D HISTECH®, Budapest, Hungary), as previously described [12]. Immunohistochemical (IHC) staining was performed on 4- $\mu \mathrm{m}$ sections using a Novolink polymer detection system (RE7280$\mathrm{K}$; Leica, Newcastle, UK). Antigen retrieval was performed by microwaving $(1000 \mathrm{~W})$ the sections in citrate buffer $(\mathrm{pH}$ 6.0 ) for $20 \mathrm{~min}$. The SLC39A6 antibody was applied at the optimal dilution (1:200) for $60 \mathrm{~min}$ at room temperature. Human kidney tissue section was used as a positive control; the negative control was obtained by omitting the primary antibody. High-resolution scanned digital images of the TMAs (NanoZoomer; Hamamatsu Photonics, Welwyn Garden City, UK; $20 \times$ magnification) were viewed using Xplore Viewer software (Philips, Belfast, UK). SLC39A6 staining was evaluated using the modified semi-quantitative histochemical scoring method (H-score) by multiplying the staining intensity ( 0 : negative/no staining; 1 : weak; 2 : medium; 3: strong) by the percentage of positively stained tumour cells (0-100\%) to generate a H-score (range, 0-300) [34]. Non-representative cores containing folded tissues, only normal adjacent breast tissues or $<15 \%$ tumour cells were not scored.

\section{Statistical analysis}

IBM SPSS 24.0 (Chicago, IL, USA) software was used for statistical analysis. SLC39A6 expression in both mRNA and protein was categorised using X-tile software (X-tile Bioinformatics Software, Yale University, version 3.6.1) based on prediction of patient outcome [35]. The associations between the categorical groups of SLC39A6 expression and clinicopathological parameters and other markers were analysed using the Chi-square test. The correlations between SLC39A6 cytoplasmic and nuclear protein expression and SLC39A6 mRNA expression were analysed using the Spearman correlation coefficient test. The associations between SLC39A6 expression and patient outcomes were assessed using Kaplan-Meier curves and the log-rank test. Cox proportional hazards regression models were built for multivariate survival analyses to estimate adjusted hazard ratios (HRs). For all statistical tests, $P<0.05$ (two-tailed) was considered significant. This study follows the Reporting Recommendations for Tumour Markers in Prognostic Studies (REMARK) criteria [36].

\section{Results}

\section{SLC39A6 mRNA expression in BC}

High SLC39A6 mRNA expression (8.5 log fold-change or greater) was observed in $1207 / 1943$ (62\%) of the entire METABRIC cohort and in 1186/1473 of the ER + tumours (79\%; $P<0.0001)$. High SLC39A6 mRNA expression was infrequent in the ER-negative tumours $(21 / 449 ; 4 \%)$. SLC39A6 CN gains were observed in 49/1980 (2.5\%) of the entire cohort and 35/1471 (2.3\%) of the ER+tumours, whereas 80/1980 (4.0\%) of the entire cohort and 66/1440 (4.4\%) of the ER + tumours exhibited CN loss, respectively.

\section{SLC39A6 protein expression in BC}

IHC analysis of full-face sections revealed homogeneous immunohistochemical staining for SLC39A6 and validated the use of TMA cores to assess SLC39A6 expression in BC. SLC39A6 immunoreactivity was observed in the cytoplasm and nuclei of the invasive epithelial tumour cells (Fig. 1A and $\mathrm{B})$.

High cytoplasmic SLC39A6 expression (cut-off, $\mathrm{H}$-score $>160)$ and high nuclear SLC39A6 expression (cut-off, H-score $>0$ ) were observed in 246/670 (37\%) and $285 / 670(43 \%)$ of the BC cases, respectively. SLC39A6 
Fig. 1 A Representative images of positive immunohistochemical staining for SLC39A6 in the cytoplasm and nuclei of $\mathrm{BC}$ cells. B Negative immunohistochemical staining for SLC39A6
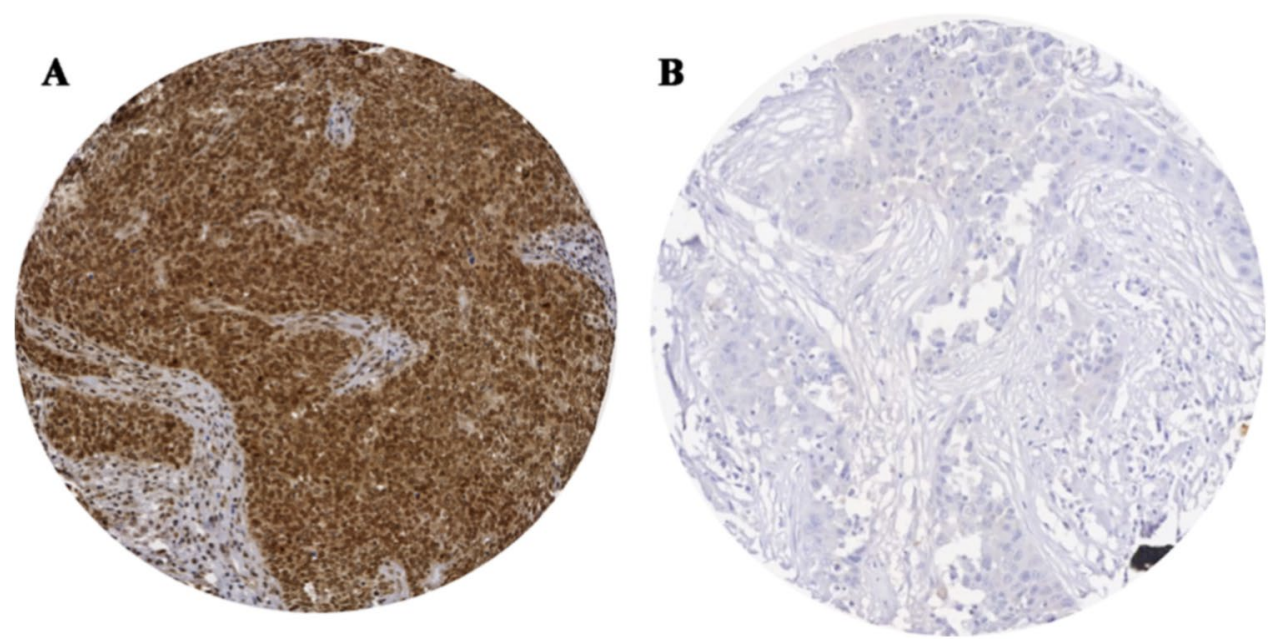

nuclear and cytoplasmic co-expression was observed in $140 / 670(21 \%)$ of the entire cohort. Moreover, a significant positive correlation was observed between SLC39A6 cytoplasmic and nuclear protein expression $(R=0.422$, $P<0.0001)$. However, amongst the cases from the Nottingham cohort that were also included in the METABRIC cohort $(n=180)$, no significant association between SLC39A6 protein expression and SLC39A6 mRNA expression was identified $(P>0.05)$.

Supplementary Table 3 summarises the mean, median and ranges of SLC39A6 cytoplasmic and nuclear expression in ER + and ER- tumours. SLC39A6 protein was expressed at significantly higher levels in ER + tumours than ERnegative tumours $(P<0.0001)$. Moreover, high SLC39A6 expression was significantly associated with the luminal A subtype, which was defined by ER +, PR +, HER2- and low Ki67 expression.

\section{Associations between SLC39A6 expression and the clinicopathological features}

High nuclear and high cytoplasmic SLC39A6 protein expression was associated with features characteristic of a good prognosis in BC, including low tumour grade ( $P<0.0001$ and $P=0.044$, respectively), low mitotic counts $(P<0.0001$, only nuclear expression), low nuclear pleomorphism $(P<0.0001$ and $P=0.027)$, good NPI $(P=0.001$ and $P=0.006)$ and early nodal stage $(P=0.004$, only nuclear expression) (Supplementary Table 4$)$. When the analysis was limited to luminal ER + tumours, high nuclear and high cytoplasmic SLC39A6 protein expression was significantly associated with low tumour grade $(P<0.0001$ and $P=0.009)$, low mitotic count $(P=0.001$, only nuclear expression), a low nuclear pleomorphism score $(P<0.0001$ and $P=0.005)$, early tumour stage $(P=0.020$, only nuclear expression) and good NPI scores $(P<0.0001$ and $P=0.014$; Table 1$)$.
In METABRIC cohort, similar association was observed at the mRNA level, with high SLC39A6 expression was associated with low tumour grade $(P<0.0001$ and $P=0.006)$ and good NPI scores (all $P<0.0001$ ) in both the entire BC cohort and the ER + subgroup (Supplementary Table 5).

In $\mathrm{Bc}-G e n E x M i n e r$ database, high expression of SLC39A6 was associated with good prognostic factors, including good NPI, older age, ER + tumour and luminal A subtype (all $P<0.0001$ ), as shown in supplementary Fig. 2. Moreover, better survival was observed in all BC, which confirms the pervious findings in the METABRIC cohort.

\section{Associations between expression of SLC39A6 and other ER-related biomarkers}

The correlations between SLC39A6 protein and mRNA expression and the expression of other ER-related markers were examined using data available for the METABRIC cohort (mRNA expression) and the biomarker repository of the Nottingham BC cohort (for protein expression). Significant positive correlations were identified between SLC39A6 expression and the expression of other ER-related markers, including PgR, FOXA1, GATA 3 and TFF1, at both the protein and mRNA levels $(P<0.05$; Tables $2 \& 3)$.

\section{Outcome analysis}

High nuclear SLC39A6 protein expression was associated with longer BCSS in the entire BC cohort $(P=0.001$; Supplementary Fig. 3); however, no significant association was observed between cytoplasmic SLC39A6 expression and BCSS $(P=0.217)$. In the ER + subgroup, both high nuclear and high cytoplasmic SLC39A6 expression were associated with significantly longer BCSS $(P=0.007 \& P=0.015$, respectively; Fig. 2). No such associations were identified in the ER- BC subgroup $(P>0.05)$. 
Table 1 Associations between nuclear and cytoplasmic SLC39A6 protein expression and the clinicopathological parameters of $\mathrm{ER}+\mathrm{BC}$

\begin{tabular}{|c|c|c|c|c|c|c|}
\hline \multirow[t]{2}{*}{ Parameter } & \multicolumn{3}{|c|}{ SLC39A6 Cytoplasmic expression } & \multicolumn{3}{|c|}{ SLC39A6 nuclear expression } \\
\hline & $\begin{array}{l}\text { Low } \\
\text { No }(\%)\end{array}$ & $\begin{array}{l}\text { High } \\
\text { No (\%) }\end{array}$ & $\begin{array}{l}\mathrm{x}^{2} \\
P \text {-value }\end{array}$ & $\begin{array}{l}\text { Low } \\
\text { No }(\%)\end{array}$ & $\begin{array}{l}\text { High } \\
\text { No }(\%)\end{array}$ & $\begin{array}{l}\mathrm{x}^{2} \\
P \text {-value }\end{array}$ \\
\hline \multicolumn{7}{|l|}{ Patient age (years) } \\
\hline$<50$ & $206(67)$ & $102(33)$ & 3.99 & $175(57)$ & $133(43)$ & 5.31 \\
\hline$\geq 50$ & $89(57)$ & $66(43)$ & 0.046 & $71(46)$ & $85(54)$ & 0.014 \\
\hline \multicolumn{7}{|l|}{ Tumour size } \\
\hline$\leq 2$ & $147(60)$ & $99(40)$ & 3.96 & $115(47)$ & $131(53)$ & 8.08 \\
\hline$>2$ & $147(69)$ & $67(31)$ & 0.047 & $129(60)$ & $86(40)$ & 0.003 \\
\hline \multicolumn{7}{|l|}{ Tumour grade } \\
\hline 1 & $43(54)$ & $36(46)$ & 9.52 & $34(43)$ & $45(57)$ & 26.88 \\
\hline 2 & $106(60)$ & $72(40)$ & 0.009 & $75(42)$ & $103(57)$ & $<0.0001$ \\
\hline 3 & $145(71)$ & $58(29)$ & & $136(67)$ & $68(33)$ & \\
\hline \multicolumn{7}{|l|}{ Tubule formation } \\
\hline 1 & $16(64)$ & $9(36)$ & 7.08 & $13(52)$ & $12(48)$ & 0.073 \\
\hline 2 & $102(57)$ & $74(43)$ & 0.029 & $95(52)$ & $85(47)$ & 0.964 \\
\hline 3 & $169(70)$ & $77(30)$ & & $131(54)$ & $112(46)$ & \\
\hline \multicolumn{7}{|l|}{ Mitotic count } \\
\hline 1 & $93(57)$ & $69(43)$ & 5.127 & $70(43)$ & $92(57)$ & 14.13 \\
\hline 2 & $73(68)$ & $35(32)$ & 0.077 & $56(52)$ & $52(48)$ & 0.001 \\
\hline 3 & $121(68)$ & $56(32)$ & & $113(64)$ & $65(36)$ & \\
\hline \multicolumn{7}{|l|}{ Nuclear pleomorphism } \\
\hline 1 & $2(40)$ & $3(60)$ & 10.55 & $0(0)$ & $5(100)$ & 25.84 \\
\hline 2 & $118(57)$ & $89(43)$ & 0.005 & $88(42)$ & $119(58)$ & $<0.0001$ \\
\hline 3 & $166(71)$ & $86(29)$ & & $150(64)$ & $85(36)$ & \\
\hline \multicolumn{7}{|l|}{ Axillary nodal stage } \\
\hline 1 (axillary node negative) & $178(63)$ & $106(37)$ & 4.49 & $140(49)$ & $145(51)$ & 7.81 \\
\hline 2 (1-3 positive nodes) & $85(62)$ & $52(38)$ & 0.106 & $77(56)$ & $60(44)$ & 0.020 \\
\hline 3 ( $\geq 4$ positive nodes) & $31(80)$ & $8(20)$ & & $28(72)$ & $11(28)$ & \\
\hline \multicolumn{7}{|l|}{ Nottingham Prognostic Index } \\
\hline Good Prognostic Group & $86(56)$ & $68(44)$ & 8.50 & $62(40)$ & $92(60)$ & 19.26 \\
\hline Moderate Prognostic Group & $159(66)$ & $82(34)$ & 0.014 & $136(56)$ & $106(44)$ & $<0.0001$ \\
\hline Poor Prognostic Group & $49(75)$ & $16(24)$ & & $46(71)$ & $19(29)$ & \\
\hline \multicolumn{7}{|l|}{ Vascular invasion status } \\
\hline Negative & $186(65)$ & $102(35)$ & 0.15 & $151(52)$ & $137(48)$ & 0.07 \\
\hline Positive & $108(63)$ & $64(37)$ & 0.698 & $93(54)$ & $80(46)$ & 0.782 \\
\hline
\end{tabular}

$P<0.05$ is consider significant
When the Nottingham cohort was classified into four groups based on the combination of SLC39A6 nuclear and cytoplasmic expression: (nuclear ${ }^{\text {low }} /$ cytoplasmic $^{\text {low }}$ ), (nuclear $^{\text {high/cytoplasmic }}{ }^{\text {low }}$ ), (nuclear ${ }^{\text {high/cytoplasmic }}{ }^{\text {high }}$ ) and (nuclear ${ }^{\text {low } / c y t_{0}}$ lasmic ${ }^{\text {high }}$ ), the (nuclear high/cytoplasmic ${ }^{\text {high }}$ ) group showed better BCSS in comparison to all other subgroups in both the entire $\mathrm{BC}$ cohort $(P=0.010)$ and in the ER + subgroup ( $P=0.014$; Fig. 3$)$.

In METABRIC cohort, Similar results were obtained for SLC39A6 mRNA, as high SLC39A6 expression was associated with favourable BCSS in both the entire BC cohort and $\mathrm{ER}+$ tumours $(P<0.001$ and $P=0.041$; Supplementary Fig. 4), but not in ER- tumours $(P>0.05)$. SLC39A6 CN gain was also associated with significantly poorer BCSS in the whole cohort and subgroup of ER + tumours $(P<0.0001$ and $P=0.001$, respectively; Supplementary Fig. 5).

The Bc-GenExMiner database showed that SLC39A6 mRNA expression was associated with good overall survival and distant free survival $(P<0.0001$; Supplementary Fig. 6).

\section{Multivariate analysis}

In the multivariate Cox regression model including standard prognostic factors including patient age, tumour grade and tumour size, high SLC39A6 nuclear expression did not show significant prognostic value in the entire $\mathrm{BC}$ cohort 
Table 2 Associations between cytoplasmic and nuclear SLC39A6 protein expression and expression of other ER-related markers

\begin{tabular}{|c|c|c|c|c|c|c|}
\hline \multirow[b]{2}{*}{ Biomarker status } & \multicolumn{3}{|c|}{ SLC39A6 cytoplasmic expression } & \multicolumn{3}{|c|}{ SLC39A6 nuclear expression } \\
\hline & $\begin{array}{l}\text { Low } \\
\text { No }(\%)\end{array}$ & $\begin{array}{l}\text { High } \\
\text { No }(\%)\end{array}$ & $\begin{array}{l}\mathrm{X}^{2} \\
P \text {-value }\end{array}$ & $\begin{array}{l}\text { No }(\%) \\
\text { Low }\end{array}$ & $\begin{array}{l}\text { High } \\
\text { No (\%) }\end{array}$ & $\begin{array}{l}\mathrm{X}^{2} \\
P \text {-value }\end{array}$ \\
\hline \multicolumn{7}{|l|}{ PgR status } \\
\hline Low & $201(68)$ & $213(59)$ & 5.68 & $93(32)$ & $176(49)$ & 25.14 \\
\hline High & $93(32)$ & $146(41)$ & 0.017 & $201(68)$ & $184(51)$ & $<0.0001$ \\
\hline \multicolumn{7}{|l|}{ FOXA1 status } \\
\hline Low & $184(64)$ & $104(59)$ & 1.06 & $198(69)$ & $66(37)$ & 44.21 \\
\hline High & $104(36)$ & $72(41)$ & 0.301 & $90(31)$ & $111(63)$ & $<0.0001$ \\
\hline \multicolumn{7}{|l|}{ GATA3 status } \\
\hline Low & $224(67)$ & $51(56)$ & 3.36 & $210(63)$ & $44(48)$ & 6.10 \\
\hline High & $111(33)$ & $40(44)$ & $\mathbf{0 . 0 3 8}$ & $125(37)$ & $47(52)$ & 0.013 \\
\hline \multicolumn{7}{|l|}{ TFF1 status } \\
\hline Low & $146(67)$ & $100(54)$ & 7.35 & $146(67)$ & $84(45)$ & 18.99 \\
\hline High & $71(33)$ & $85(46)$ & 0.007 & $72(33)$ & $101(55)$ & $<0.0001$ \\
\hline
\end{tabular}

$P<0.05$ is consider significant

Table 3 Associations between SLC39A6 mRNA expression and the mRNA expression levels of other ER-related markers

\begin{tabular}{llll}
\hline \multirow{2}{*}{ Biomarker status } & \multicolumn{3}{l}{ SLC39A6 mRNA expression } \\
\cline { 2 - 4 } & $\begin{array}{l}\text { Low } \\
\text { No }(\%)\end{array}$ & $\begin{array}{l}\text { High } \\
\text { No }(\%)\end{array}$ & $\begin{array}{l}X^{2} \\
P \text {-value }\end{array}$ \\
\hline PgR status & & \\
Low & $577(78)$ & $345(29)$ & 454.98 \\
High & $159(22)$ & $862(71)$ & $<\mathbf{0 . 0 0 0 1}$ \\
FOXA1 status & & & \\
Low & $392(55)$ & $55(5)$ & 624.46 \\
High & $326(45)$ & $1137(95)$ & $<\mathbf{0 . 0 0 0 1}$ \\
GATA3 status & & & \\
Low & $533(74)$ & $164(14)$ & 694.42 \\
High & $186(26)$ & $1011(86)$ & $<\mathbf{0 . 0 0 0 1}$ \\
TFF1 status & & & \\
Low & $576(79)$ & $385(32)$ & 386.27 \\
High & $158(21)$ & $805(68)$ & $<\mathbf{0 . 0 0 0 1}$ \\
\hline
\end{tabular}

$P<0.05$ is consider significant

$(P=0.05)$. However, in the luminal ER + tumours, high SLC39A6 nuclear expression was an independent predictor of longer BCSS $(P=0.034$, HR 0.678, 95\% CI 0.472-0.972; Supplementary Table 6). Moreover, when the Cox regression model was restricted to ER + tumours and incorporated other ER-related proteins, nuclear SLC39A6 expression remained as the only independent prognostic factor for BCSS ( $P=0.002$; Supplementary Table 7).

Regarding the prognostic value of SLC39A6 mRNA expression, the multivariate Cox regression model including same standard prognostic factors showed its expression to be an independent predictor of BCSS in both the entire cohort $(P=0.001, \mathrm{HR}=0.727,95 \% \mathrm{Cl}=0.598-0.884)$ and the ER + tumours $(P=0.029, \mathrm{HR}=0.913,95 \%$ $\mathrm{Cl}=0.841-0.991$; Supplementary Table 8 ). The prognostic value of SLC39A6 mRNA for BCSS in the entire cohort was also maintained when other ER-related markers were included in the Cox regression model $(P=0.034$, $\mathrm{HR}=0.918,95 \% \mathrm{Cl}=0.847-0.994$; Supplementary Table 9).

\section{Associations between SLC39A6 and the response to endocrine therapy}

As high SLC39A6 expression was associated with a good prognosis and outcome in patients with $\mathrm{ER}+\mathrm{BC}$, we hypothesised that the prognostic value of SLC39A6 is dependent on hormone therapy targeting the ER. Thus, we examined the associations between SLC39A6 expression and recurrences (RFS and DMFS) and survival (BCSS) in the subgroup of the endocrine-therapy naïve ER + BC patients $(n=190)$. In those patients with $\mathrm{ER}+\mathrm{BC}$ who did not receive endocrine therapy, high SLC39A6 protein expression remained its association with longer BCSS $(P=0.001$, HR 0.701 , 95\% CI 0.463-1.062; Supplementary Fig. 7) and DMFS $(P=0.027$, HR 0.784, 95\% CI 0.533-1.151; Supplementary Fig. 8) compared to patients with low SLC39A6 expression.

\section{Discussion}

The luminal ER + class of BC, which is the most common subtype comprising approximately $70 \%$ of cases, is associated with a better prognosis compared to the ER- and triple negative classes. However, ER + tumours exhibit 

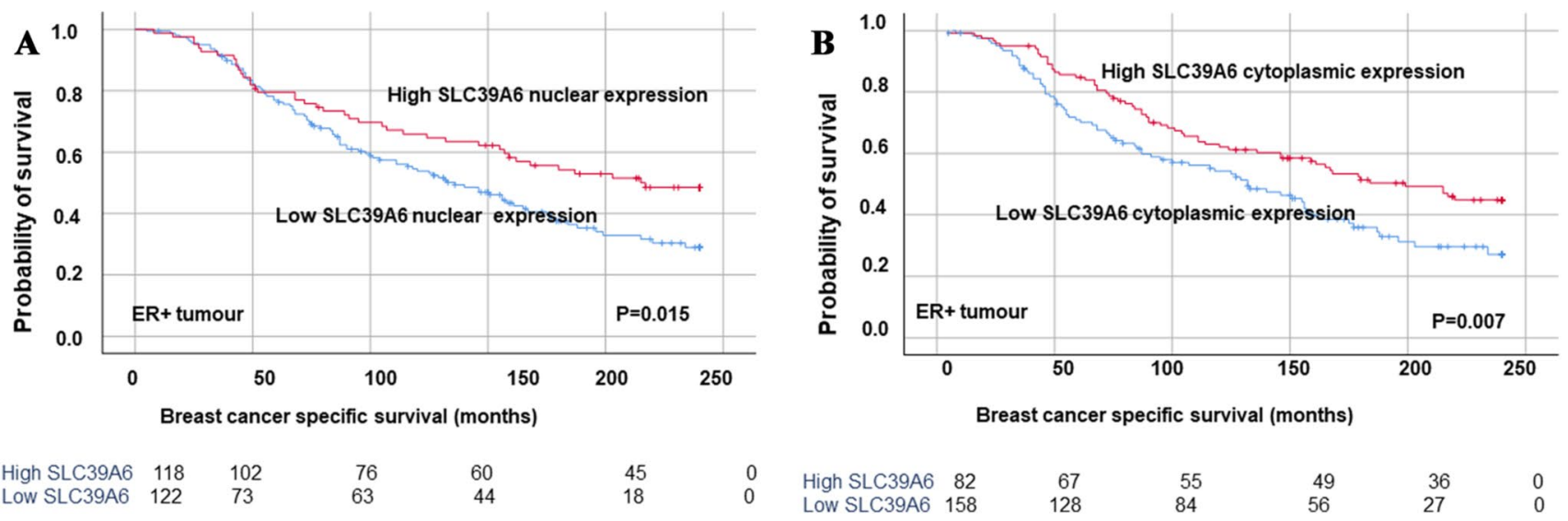

Fig. 2 Kaplan-Meier plots of the associations between high SLC39A6 (A) nuclear and B cytoplasmic protein expression and breast cancerspecific survival (BCSS) in oestrogen receptor-positive breast cancer

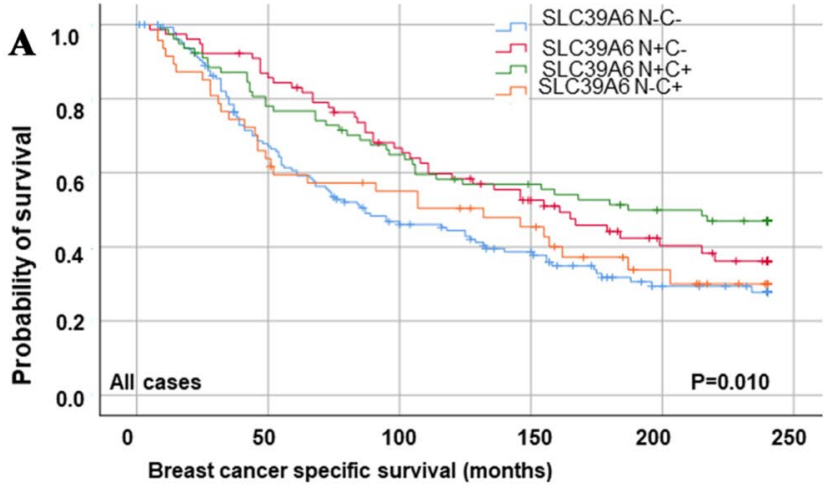

SLC39A6 N-C- 148 SLC39A6 N+C- 76 SLC39A6 $\mathrm{N}+\mathrm{C}+77$ SLC39A6N-C+ 46

$\begin{array}{ll}94 & 60 \\ 65 & 47 \\ 60 & 48 \\ 30 & 24\end{array}$

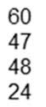

43
33
41
17

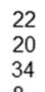

Fig. 3 A Kaplan-Meier survival plots showing combination of SCL39A6 cytoplasmic (C) + and nuclear (N) + expression class associated with longer breast cancer-specific survival (BCSS) compare to other classes in ER + BC tumours A\&B, respectively

considerable morphological and molecular heterogeneity and the patients have varied prognoses, therapeutic responses and survival outcomes [36-39]. A better understanding of the varied molecular and biological behaviours of ER + BC may help to further refine prognostic models and more accurately predict the response of individual patients to adjuvant treatment. Thus, we quantified SLC39A6 at the proteomic, transcriptomic and genomic levels in two large cohorts in order to assess the prognostic value of this ERrelated marker in $\mathrm{BC}$.

McClelland et al. (1998) reported a high frequency of high SLC39A6 protein expression (70\%) and a low frequency of high SLC39A6 mRNA expression (28\%) in a small BC cohort $(n=44)$ [17]. Another study $(n=111)$ detected SLC39A6 using IHC and in situ hybridisation (ISH) in $28 \%$ and $53 \%$ of BC cases, respectively [26]. These discrepancies could be explained by the limited numbers of cases, as

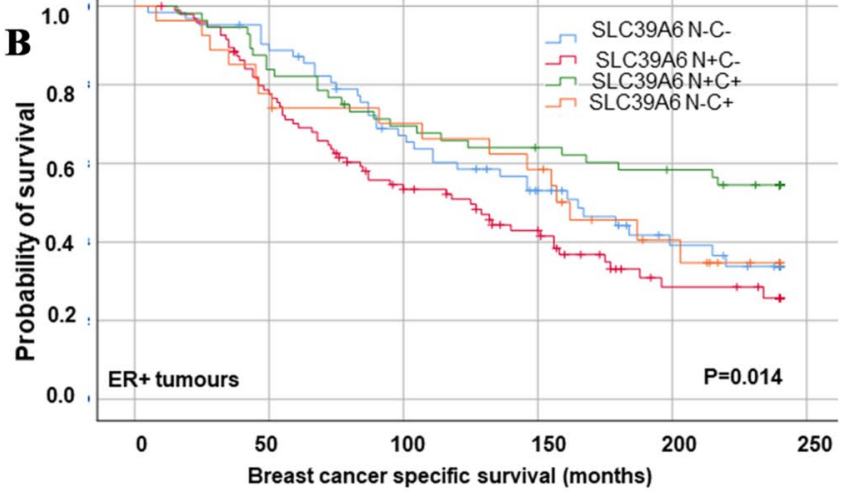

$\begin{array}{lccccc}\text { SLC39A6 N-C - } 94 & 72 & 45 & 29 & 12 & 0 \\ \text { SLC39A6 N+C- } 62 & 55 & 38 & 26 & 15 & 0 \\ \text { SLC39A6 N+C+ 55 } & 47 & 37 & 34 & 30 & 0 \\ \text { SLC39A6 N-C + } 26 & 20 & 17 & 14 & 6 & 0\end{array}$

$\mathrm{SLC} 39 \mathrm{~A} 6 \mathrm{~N}+\mathrm{C}+55$

SLC39A6 N-C + 26 well as differences in the scoring systems and primary antibodies between studies. In the current study, high cytoplasmic SLC39A6 protein expression, high nuclear SLC39A6 protein expression and high SLC39A6 mRNA expression were observed in $43 \%, 37 \%$ and $50 \%$ of the BC tumours overall, respectively. Therefore, variability in the percentage of positive cases in the studies can be explained not only the number of cases but also by the subcellular location of the proteins with overlap between nuclear and cytoplasmic expression as $20 \%$ of cases showed combined expression. Although no significant correlation was observed between SLC39A6 protein and mRNA expression in this study, this could be explained by post-transcriptional mechanisms which regulate SLC39A6 protein expression but these have not yet been described.

SLC39A6 has been described as an oestrogen-inducible gene that is upregulated in $\mathrm{ER}+\mathrm{BC}$ [11]. A previous study 
reported that SLC39A6 expression was associated with $\mathrm{ER}+$ status in BC [12]. This study confirms that both high SLC39A6 mRNA and protein expression are observed more frequently in ER + tumours than ER-negative tumours. Previous in vitro studies suggested that SLC39A6 is associated with progression in $\mathrm{BC}$ by facilitating zinc influx into tumour cells, which subsequently promotes tumour growth and the EMT [40, 41]. Hogstrand et al. (2013) predicted that the N-terminus of SLC39A6 is located in the endoplasmic reticulum. Furthermore, knockdown of SLC39A6 using a siRNA upregulated STAT3 expression [15], which suggests that SLC39A6 localised to the endoplasmic reticulum plays a distinct role in $\mathrm{BC}$.

This study also indicates that high cytoplasmic and high nuclear SLC39A6 protein expression and high SLC39A6 mRNA expression were associated with classical clinicopathological parameters characteristic of a less aggressive tumours and a better outcome, especially in the ER + subgroup. These observations are consistent with a previous report, which showed low SLC39A6 protein expression was associated with larger tumour size, high grade and advanced tumour stage in BC [26]. Importantly this study demonstrated that high nuclear SLC39A6 expression is an independent predictor of good outcome. The survival analysis and analysis of clinicopathological features in this study also suggest cytoplasmic and nuclear SLC39A6 exert distinct roles, especially in ER + tumours. For example, oestrogen has been suggested to lead to $\mathrm{N}$-terminal cleavage and activation of SLC39A6, which enables trafficking of the protein to the cell membrane [15]. Moreover, high SLC39A6 expression may alter zinc homeostasis in BC cells, which may in turn promote tumour cell metabolism and enable the development and progression of cancer [13].

We also assessed the correlations between the expression of SLC39A6 and other well-characterised ER-related markers that have been identified as signature genes in ER + tumours, including FOXA1 and GATA3 [8, 38]. FOXA1 facilitates the interactions between transcription factors such as the ER and DNA, as FOXA1 can occupy compacted DNA in the absence of other interacting proteins [42]. A previous IHC study identified a strong association between high ER expression and high FOXA1 expression in BC [43]. Inhibition of GATA3 can direct the ER to DNA binding sites surrounded by FOXA1 [44], a downstream effector of GATA3 [45]. Moreover, TFF1 and PgR have both been identified as biomarkers of a better prognosis in ER + tumours $[46,47]$. This work further strengthens the associations between SLC39A6 expression and GATA3, TFF1 and PgR in BC.

McClelland et al. (1998) previously reported that in $\mathrm{ER}+$ tumours, SLC39A6 was associated with a variable response to endocrine therapy [17].This study indicates SLC39A6 is associated with a longer survival in ER + BC patients who did not receive hormone therapy more than who were given such treatment. These results are interesting and warrant further investigation. SLC39A6 may inhibit the ER in patients undergoing endocrine therapy, and also suggests that patients with ER + tumours expressing high levels of SLC39A6 may be candidate for a different type of endocrine treatment to further improve their outcome. AS SLC39A6 was not associated with outcome in ER- BC, this study also suggest that the ER inhibits the pro-tumorigenic and EMT-promoting effects of SLC39A6. However, when endocrine therapy inhibits the ER functions, then the proproliferative/pro-EMT effects of SLC39A6 are restored and the association with a better outcome observed in the $\mathrm{ER}+$ tumours becomes not significant. However, future experimental studies are required to identify the precise mechanisms underlying the interplay between various types of endocrine therapy and SLC39A6 expression in ER + BC.

\section{Conclusion}

SLC39A6 may have prognostic value in BC, especially in ER + tumours. Further assessment of SLC39A6 may help to more accurately stratify patients with ER $+\mathrm{BC}$ and identify patients who may achieve a good outcome.

Supplementary Information The online version contains supplementary material available at https://doi.org/10.1007/s10549-021-06336-y.

Acknowledgements We thank the University of Nottingham (Nottingham Life Cycle 6) for funding. The authors are part of the PathLAKE digital pathology consortium. These new Centres are supported by a $£ 50 \mathrm{~m}$ investment from the Data to Early Diagnosis and Precision Medicine strand of the government's Industrial Strategy Challenge Fund, managed and delivered by UK Research and Innovation (UKRI). Maryam Althobiti is supported and funded by Saudi cultural bureau, and Shaqra University.

Data availability The dataset analysed during the current study is available from the corresponding author on reasonable request.

\section{Declarations}

Conflicts of interest The authors declare that they have no conflict of interests.

Ethical approval The experiments comply with the current laws of the country in which they were performed.

Informed consent All tissue samples from Nottingham used in this study were pseudo-anonymised and collected prior to 1st September 2006; therefore, under the UK Human Tissue Act informed patient consent was not needed.

Research involving human participants and/or animals This study was approved by the Nottingham Research Ethics Committee 2 under the title 'Development of a molecular genetic classification of breast 
cancer' and the North West - Greater Manchester Central Research Ethics Committee under the title 'Nottingham Health Science Biobank (NHSB)' reference number 15/NW/0685. All procedures performed in studies involving human participants were in accordance with the ethical standards of the institutional and/or national research committee and with the 1964 Helsinki declaration and its later amendments or comparable ethical standards. Release of data was also pseudoanonymised as per the UK Human Tissue Act regulations. This article does not contain any studies with animals performed by any of the authors.

Open Access This article is licensed under a Creative Commons Attribution 4.0 International License, which permits use, sharing, adaptation, distribution and reproduction in any medium or format, as long as you give appropriate credit to the original author(s) and the source, provide a link to the Creative Commons licence, and indicate if changes were made. The images or other third party material in this article are included in the article's Creative Commons licence, unless indicated otherwise in a credit line to the material. If material is not included in the article's Creative Commons licence and your intended use is not permitted by statutory regulation or exceeds the permitted use, you will need to obtain permission directly from the copyright holder. To view a copy of this licence, visit http://creativecommons.org/licenses/by/4.0/.

\section{References}

1. Voduc D, Cheang M, Nielsen T (2008) GATA-3 expression in breast cancer has a strong association with estrogen receptor but lacks independent prognostic value. Cancer Epidemiol, Biomark Prevention : A Publ Am Assoc Cancer Res, Cosponsored Am Soc Prev Oncol 17(2):365-373

2. Garcia-Becerra R, Santos N, Diaz L, Camacho J (2012) Mechanisms of resistance to endocrine therapy in breast cancer: focus on signaling pathways, miRNAs and genetically based resistance. Int J Mol Sci 14(1):108-145

3. Kjallquist U, Erlandsson R, Tobin NP, Alkodsi A, Ullah I, Stalhammar G, Karlsson E, Hatschek T, Hartman J, Linnarsson S et al (2018) Exome sequencing of primary breast cancers with paired metastatic lesions reveals metastasis-enriched mutations in the A-kinase anchoring protein family (AKAPs). BMC Cancer 18(1):174

4. Kumar B, Prasad M, Bhat-Nakshatri P, Anjanappa M, Kalra M, Marino N, Storniolo AM, Rao X, Liu S, Wan J et al (2018) Normal breast-derived epithelial cells with luminal and intrinsic subtype-enriched gene expression document interindividual differences in their differentiation cascade. Can Res 78(17):5107-5123

5. Pereira B, Chin SF, Rueda OM, Vollan HK, Provenzano E, Bardwell HA, Pugh M, Jones L, Russell R, Sammut SJ et al (2016) Erratum: the somatic mutation profiles of 2,433 breast cancers refine their genomic and transcriptomic landscapes. Nat Commun 7:11908

6. Curtis C, Shah SP, Chin S-F, Turashvili G, Rueda OM, Dunning MJ, Speed D, Lynch AG, Samarajiwa S, Yuan Y et al (2012) The genomic and transcriptomic architecture of 2,000 breast tumours reveals novel subgroups. Nature 486(7403):346-352

7. Yip CH, Rhodes A (2014) Estrogen and progesterone receptors in breast cancer. Future Oncol (Lond, Eng) 10(14):2293-2301

8. Chaudhary S, Krishna BM, Mishra SK (2017) A novel FOXA1/ ESR1 interacting pathway: a study of Oncomine breast cancer microarrays. Oncol Lett 14(2):1247-1264

9. Haynes BP, Ginsburg O, Gao Q, Folkerd E, Afentakis M, Buus R, Quang LH, Thi Han P, Khoa PH, Dinh NV et al (2019) Menstrual cycle associated changes in hormone-related gene expression in oestrogen receptor positive breast cancer. NPJ breast cancer 5:42

10. Andres SA, Brock GN, Wittliff JL (2013) Interrogating differences in expression of targeted gene sets to predict breast cancer outcome. BMC Cancer 13(1):326

11. Tozlu S, Girault I, Vacher S, Vendrell J, Andrieu C, Spyratos F, Cohen P, Lidereau R, Bieche I (2006) Identification of novel genes that co-cluster with estrogen receptor alpha in breast tumor biopsy specimens, using a large-scale real-time reverse transcription-PCR approach. Endocr Relat Cancer 13(4):1109-1120

12. Abd El-Rehim DM, Ball G, Pinder SE, Rakha E, Paish C, Robertson JF, Macmillan D, Blamey RW, Ellis IO (2005) High-throughput protein expression analysis using tissue microarray technology of a large well-characterised series identifies biologically distinct classes of breast cancer confirming recent cDNA expression analyses. Int J Cancer 116(3):340-350

13. Grattan BJ, Freake HC (2012) Zinc and cancer: implications for LIV-1 in breast cancer. Nutrients 4(7):648-675

14. Taylor KM, Morgan HE, Johnson A, Hadley LJ, Nicholson RI (2003) Structure-function analysis of LIV-1, the breast cancerassociated protein that belongs to a new subfamily of zinc transporters. Biochem J 375(Pt 1):51-59

15. Hogstrand C, Kille P, Ackland ML, Hiscox S, Taylor KM (2013) A mechanism for epithelial-mesenchymal transition and anoikis resistance in breast cancer triggered by zinc channel ZIP6 and STAT3 (signal transducer and activator of transcription 3). Biochem J 455(2):229-237

16. Gaither LA, Eide DJ (2001) Eukaryotic zinc transporters and their regulation. Biometals : An Int J Role Metal Ions Biol, Biochem, Med 14(3-4):251-270

17. McClelland RA, Manning DL, Gee JM, Willsher P, Robertson JF, Ellis IO, Blamey RW, Nicholson RI (1998) Oestrogen-regulated genes in breast cancer: association of pLIV1 with response to endocrine therapy. Br J Cancer 77(10):1653-1656

18. Taylor KM, Morgan HE, Smart K, Zahari NM, Pumford S, Ellis IO, Robertson JFR, Nicholson RI (2007) The emerging role of the LIV-1 subfamily of zinc transporters in breast cancer. Mol Med 13(7-8):396-406

19. Shen H, Qin H, Guo J (2009) Concordant correlation of LIV-1 and E-cadherin expression in human breast cancer cell MCF-7. Mol Biol Rep 36(4):653-659

20. Truong-Tran AQ, Carter J, Ruffin RE, Zalewski PD (2001) The role of zinc in caspase activation and apoptotic cell death. Biometals : an Int J Role Metal Ions Biol, Biochem Med 14(3-4):315-330

21. El Ansari R, Craze ML, Miligy I, Diez-Rodriguez M, Nolan CC, Ellis IO, Rakha EA, Green AR (2018) The amino acid transporter SLC7A5 confers a poor prognosis in the highly proliferative breast cancer subtypes and is a key therapeutic target in luminal B tumours. Breast Cancer Res 20(1):21

22. Lue HW, Yang X, Wang R, Qian W, Xu RZ, Lyles R, Osunkoya AO, Zhou BP, Vessella RL, Zayzafoon M et al. (2011) LIV- 1 promotes prostate cancer epithelial-to-mesenchymal transition and metastasis through HB-EGF shedding and EGFR-mediated ERK signaling. PloS one 6(11):e27720

23. Unno J, Satoh K, Hirota M, Kanno A, Hamada S, Ito H, Masamune A, Tsukamoto N, Motoi F, Egawa S et al (2009) LIV-1 enhances the aggressive phenotype through the induction of epithelial to mesenchymal transition in human pancreatic carcinoma cells. Int J Oncol 35(4):813-821

24. Zhao L, Chen W, Taylor KM, Cai B, Li X (2007) LIV-1 suppression inhibits HeLa cell invasion by targeting ERK1/2-Snail/Slug pathway. Biochem Biophys Res Commun 363(1):82-88

25. Shen R, Xie F, Shen H, Liu Q, Zheng T, Kou X, Wang D, Yang J (2013) Negative correlation of LIV-1 and E-cadherin expression in hepatocellular carcinoma cells. PloS one 8(2):e56542 
26. Kasper G, Weiser AA, Rump A, Sparbier K, Dahl E, Hartmann A, Wild P, Schwidetzky U, Castanos-Velez E, Lehmann K (2005) Expression levels of the putative zinc transporter LIV-1 are associated with a better outcome of breast cancer patients. Int J Cancer 117(6):961-973

27. Taylor KM (2008) A distinct role in breast cancer for two LIV-1 family zinc transporters. Biochem Soc Trans 36(Pt 6):1247-1251

28. Jézéquel P, Campone M, Gouraud W, Guérin-Charbonnel C, Leux C, Ricolleau G, Campion L (2012) bc-GenExMiner: an easy-touse online platform for gene prognostic analyses in breast cancer. Breast Cancer Res Treat 131(3):765-775

29. Althobiti M, Aleskandarany MA, Joseph C, Toss M, Mongan N, Diez-Rodriguez M, Nolan CC, Ashankyty I, Ellis IO, Green AR et al (2018) Heterogeneity of tumour-infiltrating lymphocytes in breast cancer and its prognostic significance. Histopathology 73(6):887-896

30. Galea MH, Blamey RW, Elston CE, Ellis IO (1992) The Nottingham prognostic index in primary breast cancer. Breast Cancer Res Treat 22(3):207-219

31. Habashy HO, Powe DG, Rakha EA, Ball G, Paish C, Gee J, Nicholson RI, Ellis IO (2008) Forkhead-box A1 (FOXA1) expression in breast cancer and its prognostic significance. Eur J Cancer 44(11):1541-1551

32. Rakha EA, Pinder SE, Bartlett JM, Ibrahim M, Starczynski J, Carder PJ, Provenzano E, Hanby A, Hales S, Lee AH et al (2015) Updated UK recommendations for HER2 assessment in breast cancer. J Clin Pathol 68(2):93-99

33. Muftah AA, Aleskandarany MA, Al-Kaabi MM, Sonbul SN, Diez-Rodriguez M, Nolan CC, Caldas C, Ellis IO, Rakha EA, Green AR (2017) Ki67 expression in invasive breast cancer: the use of tissue microarrays compared with whole tissue sections. Breast Cancer Res Treat 164(2):341-348

34. McCarty KS Jr, Miller LS, Cox EB, Konrath J, McCarty KS Sr (1985) Estrogen receptor analyses Correlation of biochemical and immunohistochemical methods using monoclonal antireceptor antibodies. Arch Pathol Lab Med 109(8):716-721

35. Camp RL, Dolled-Filhart M, Rimm DL (2004) X-tile: a new bioinformatics tool for biomarker assessment and outcome-based cut-point optimization. Clin Cancer Res 10(21):7252-7259

36. McShane LM, Altman DG, Sauerbrei W, Taube SE, Gion M, Clark GM (2005) REporting recommendations for tumour MARKer prognostic studies (REMARK). Br J Cancer 93(4):387-391
37. Aleskandarany MA, Vandenberghe ME, Marchio C, Ellis IO, Sapino A, Rakha EA (2018) Tumour heterogeneity of breast cancer: from morphology to personalised medicine. Pathobiol: J Immunopathol, Mol Cellular Biol 85(1-2):23-34

38. Perou CM, Sorlie T, Eisen MB, van de Rijn M, Jeffrey SS, Rees CA, Pollack JR, Ross DT, Johnsen H, Akslen LA et al (2000) Molecular portraits of human breast tumours. Nature 406(6797):747-752

39. Sorlie T, Perou CM, Tibshirani R, Aas T, Geisler S, Johnsen H, Hastie T, Eisen MB, van de Rijn M, Jeffrey SS et al (2001) Gene expression patterns of breast carcinomas distinguish tumor subclasses with clinical implications. Proc Natl Acad Sci USA 98(19):10869-10874

40. Taylor KM, Hiscox S, Nicholson RI (2004) Zinc transporter LIV1: a link between cellular development and cancer progression. Trends Endocrinol Metab 15(10):461-463

41. Lopez V, Kelleher SL (2010) Zip6-attenuation promotes epithelial-to-mesenchymal transition in ductal breast tumor (T47D) cells. Exp Cell Res 316(3):366-375

42. Carroll JS (2016) Mechanisms of oestrogen receptor (ER) gene regulation in breast cancer. Eur J Endocrinol 175(1):R41-R49

43. Rangel N, Fortunati N, Osella-Abate S, Annaratone L, Isella C, Catalano MG, Rinella L, Metovic J, Boldorini R, Balmativola D et al (2018) FOXA1 and AR in invasive breast cancer: new findings on their co-expression and impact on prognosis in ERpositive patients. BMC Cancer 18(1):703-703

44. Theodorou V, Stark R, Menon S, Carroll JS (2013) GATA3 acts upstream of FOXA1 in mediating ESR 1 binding by shaping enhancer accessibility. Genome Res 23(1):12-22

45. Kouros-Mehr H, Slorach EM, Sternlicht MD, Werb Z (2006) GATA-3 maintains the differentiation of the luminal cell fate in the mammary gland. Cell 127(5):1041-1055

46. Corte MD, Tamargo F, Alvarez A, Rodriguez JC, Vazquez J, Sanchez R, Lamelas ML, Gonzalez LO, Allende MT, GarciaMuniz JL et al (2006) Cytosolic levels of TFF1/pS2 in breast cancer: their relationship with clinical-pathological parameters and their prognostic significance. Breast Cancer Res Treat 96(1):63-72

47. Zheng ZY, Bay BH, Aw SE, Lin VC (2005) A novel antiestrogenic mechanism in progesterone receptor-transfected breast cancer cells. J Biol Chem 280(17):17480-17487

Publisher's Note Springer Nature remains neutral with regard to jurisdictional claims in published maps and institutional affiliations. 